\title{
Clinical study of role of ultrasound in first trimester vaginal bleeding
}

\author{
Sandyashree P. K.*, Swathi Nayak C. V.
}

Department of Obstetrics and Gynaecology, Mandya Institute of Medical Sciences, Mandya, Karnataka, India

Received: 05 January 2020

Revised: 09 September 2020

Accepted: 10 September 2020

\section{*Correspondence:}

Dr. Sandyashree P. K.,

E-mail: sandyashreepandith@gmail.com

Copyright: (C) the author(s), publisher and licensee Medip Academy. This is an open-access article distributed under the terms of the Creative Commons Attribution Non-Commercial License, which permits unrestricted non-commercial use, distribution, and reproduction in any medium, provided the original work is properly cited.

\begin{abstract}
Background: Vaginal bleeding is a serious cause which needs an emergency consultation. Major causes are abortion, ectopic pregnancy and molar pregnancy others like cervical erosion, polyp and carcinoma. The objective is to identify cause, assess the prognosis and institute appropriate management.

Methods: Prospective study in MMC and RI, OBG, Mysore from November 2015 to September 2017. General physical and pelvic examination done for provisional clinical diagnosis and subjected to Ultrasound. Clinical diagnosis and ultrasound diagnosis were correlated.

Results: 100 cases of first trimester bleeding evaluated by Ultrasonography with an incidence $2.37 \%$. Most common cause was abortion $(81.6 \%)$ then molar $(10 \%)$ and ectopic pregnancy $(9 \%)$. Out of 100 cases, 72 cases confirmed, 28 cases proved by ultrasound which was misdiagnosed on clinical examination with disparity of 72 between clinical and ultrasound diagnosis. 13 cases viable pregnancy by ultrasonography with sensitivity, specificity, NPV and PPV of $100 \%$ and 69 cases nonviable pregnancies with sensitivity, specificity and NPV of $100 \%$. 9 cases ectopic pregnancy were diagnosed on ultrasound with sensitivity $100 \%$, specificity $98.9 \%$, PPV $99 \%$ and accuracy $99 \%$. Clinical diagnosis in diagnosing viable pregnancies has sensitivity $76.92 \%$, specificity $64.36 \%$ and PPV $24.39 \%$. In diagnosis nonviable pregnancies, clinical diagnosis, poor statistical correlation with sensitivity 77.58 , specificity $83.33 \%$, PPV $86.53 \%$ and NPV $72.91 \%$. Ultrasonographic diagnosis proved as very accurate on statistical correlation.

Conclusions: Ultrasound is sensitive, cost effective and non-invasive diagnostic tool in first trimester bleeding. In this study, it helped in correct diagnosis of clinically misdiagnosed cases apart from confirming the diagnosis in others.
\end{abstract}

Keywords: Abortions, First trimester bleeding, Ultrasound

\section{INTRODUCTION}

Vaginal Bleeding is one of the most frequent and a potentially serious cause which calls for an emergency consultation during pregnancy. First trimester is a dynamic period which marks ovulation, fertilization, implantation and organogenesis. Nearly $20-25 \%$ of pregnant women present with bleeding of some degree during early months of gestation. ${ }^{1}$ The major causes of bleeding during pregnancy in the first trimester include abortion, ectopic pregnancy and molar pregnancy and certain conditions unrelated to pregnancy like cervical erosion, cervical polyp and cervical carcinoma. ${ }^{2}$ By mere history or clinical examination, a definitive diagnosis is usually impossible, ultrasonography has opened new dimensions in early pregnancy complications so that specific treatment can be immediately instituted. Ultrasonography helps in the early diagnosis, appropriate management and a post evacuation follow up of molar pregnancy which with a backup of serum $\beta \mathrm{HCG}$, follow up of such cases becomes feasible. Life threatening emergency like an ectopic pregnancy when evaluated by ultrasound helps in confirming the diagnosis and also in deciding the mode of approach, conservative 
management alternatively will help preserve the fertility when possible. Ultrasound in a patient with bleeding in the first trimester helps to:

- Confirm the pregnancy.

- To know if the pregnancy is intrauterine or extra uterine.

- Assess the period of gestation.

- Helps in early detection of anembryonic pregnancy which is commonly associated with chromosomal anomalies.

- Assess the type of abortion - threatened, incomplete, complete or missed.

- Recognize any associated pelvic abnormality.

- Assess the viability of the fetus.

- To confirm or rule out suspected hydatidi form mole.

Thus, clinical examination and a non-invasive modality like ultrasonography go hand in hand and is essential to correlate, arrive at a diagnosis and provide the best possible management to the patient. In this study of 100 patients, we have evaluated the role of ultrasound and its importance in first trimester bleeding.

The purpose of this study is to show the importance of ultrasound in identifying the cause of vaginal bleeding occuring in first trimester, to assess the prognosis and to institute appropriate obstetric management.

\section{METHODS}

The study includes all obstetric cases attending department of Obstetrics and Gynecology, Cheluvamba hospital, Mysore Medical College and Research Institute with history of bleeding per vaginum in first trimester from November 2015 to September 2017. The study was approved by the institutional ethical committee, Mysore Medical College, Mysore, Karnataka, India. Sample size of 100 cases who presented with history of bleeding in first trimester of pregnancy have been included.

It is a hospital based prospective study of patients who present with bleeding per vaginum in the first trimester of pregnancy during the study period. Clinical details like age, parity, obstetric history, personal history, medical history, past history, menstrual history and details of present pregnancy in terms of period of amenorrhoea at the time of first episode of bleeding, amount and duration of bleeding whether associated with pain abdomen or not and history of expulsion of fleshy mass /clots were noted. Clinical examination including general physical examination and pelvic examination was done to arrive at a provisional clinical diagnosis.

Patients were then subjected to ultrasound examination. Data was collected in a preformed proforma. Clinical and ultrasound findings were correlated. Transvaginal sonography was done using 7-12 mhz transducer. Analysis were made based on appropriate statistical methods

\section{Inclusion criteria}

All patients who present with bleeding per vagina and admitted for the same in first trimester of pregnancy

\section{Exclusion criteria: Nil.}

\section{Statistical methods}

\section{Descriptive statistics}

The descriptive procedure displays univariate summary statistics for several variables in a single table and calculates standardized values (z scores). Variables can be ordered by the size of their means (in ascending or descending order), alphabetically, or by the order in which the researcher specifies.

Following descriptive statistics were employed in the present study-mean, standard deviation, frequency and percent.

\section{Inferential statistics}

\section{Chi-square test}

The Chi-Square Test procedure tabulates a variable into categories and computes a chi-square statistic. This goodness-of-fit test compares the observed and expected frequencies in each category to test either that all categories contain the same proportion of values or that each category contains a user-specified proportion of values.

\section{Crosstabs (Cramer's V)}

The crosstabs procedure forms two-way and multiway tables and provides a variety of tests and measures of association for two-way tables. The structure of the table and whether categories are ordered determine what test or measure to use. Cramer's V test was employed in the present study. All the statistical methods were carried out through the SPSS for Windows (version 21.0).

\section{RESULTS}

Table 1: Distribution of cases according to age.

\begin{tabular}{|lll|}
\hline Age in years & $\begin{array}{l}\text { Number of } \\
\text { patients }\end{array}$ & Percentage \\
\hline $\mathbf{1 8 - 2 0}$ & 30 & 30 \\
\hline $\mathbf{2 1 - 2 5}$ & 48 & 48 \\
\hline $\mathbf{2 6 - 3 0}$ & 14 & 14 \\
\hline $\mathbf{> 3 0}$ & 8 & 8 \\
\hline Total & 100 & 100 \\
\hline Test statistics & $\begin{array}{l}\mathrm{X}^{2}=38.56 ; \mathrm{df}=3, \\
\mathrm{p}=0.001\end{array}$ \\
\hline
\end{tabular}




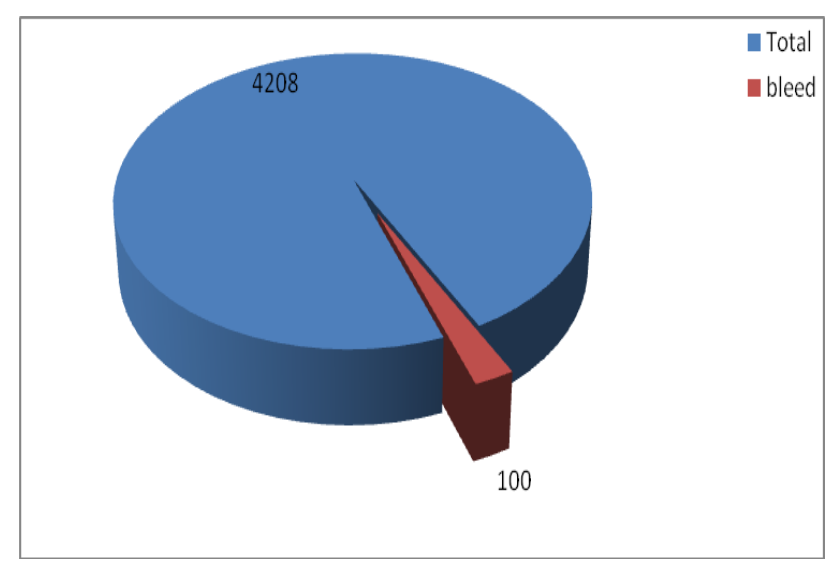

Figure 1: Representing the incidence of bleeding in first trimester.

The above Table and graph shows that total obstetric cases was 4208, out of which 100 cases had bleeding per vagina in first trimester $(2.37 \%)$.

The above table shows, majority of them in the age group of 21-25 years constitutes $48 \%$. 30 cases (30\%) in 18-20 years, $14(14 \%)$ in $26-30$ years, $8(8 \%)$ in $31-35$ years. The mean age was 23 years.

Table 2: Distribution of cases according to parity.

\begin{tabular}{|lll|}
\hline $\begin{array}{l}\text { Parity } \\
\text { distribution }\end{array}$ & Number & Percentage \\
\hline Primigravida & 33 & 33.0 \\
\hline Multigravida & 67 & 67.0 \\
\hline Total & 100 & 100.0 \\
\hline Test statistics & $\begin{array}{l}\mathrm{X}^{2}=11.56 ; \mathrm{df}=1, \\
\mathrm{p}=0.001\end{array}$ \\
\hline
\end{tabular}

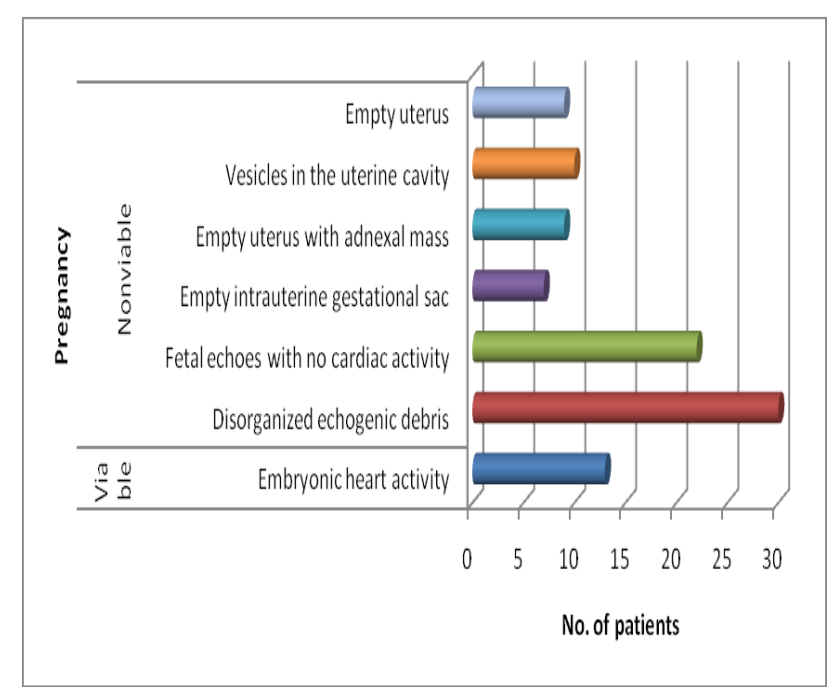

Figure 2: Displaying the ultrasonographic features of the cases in the study.

In the present study, $33(33 \%)$ primigravida and $67(67 \%)$ multigravida. Majority of cases $72(72 \%)$ had uterine size
$<10$ weeks and $16(16 \%)$ between 10-12weeks. Cervical os was open in 31(31\%) cases and closed in $69(69 \%)$ cases. Fornices was free in $92(92 \%)$ cases and tender in $8(8 \%)$ cases.

In the study as per clinical diagnosis, majority of cases, $49(49 \%)$ cases were clinically diagnosed as threatened abortion, $26(26 \%)$ cases as incomplete abortion, $9(9 \%)$ cases as missed abortion, $4(4 \%)$ cases as ectopic pregnancy, 7 case as complete abortion, 4 cases as inevitable abortion and one case as molar pregnancy.

The above graph shows the ultrasonographic features of 100 cases, $13(13 \%)$ showed signs of viable pregnancy. $30(30 \%)$ cases showed disorganised gestational sac or few echogenic debris indicating incomplete abortion. 22 (22\%) cases were visualised as fetal echoes with absence cardiac activity indicating missed abortion, 7 (7\%) showed an empty gestational sac with no fetal pole indicating anembryonic gestation which is totally a sonographic diagnosis. In $9(9 \%)$ cases uterus was empty but with an adnexal mass hence diagnosed as ectopic pregnancy, 9 (9\%) cases with empty uterus was suggestive of complete abortion, $10(10 \%)$ cases were diagnosed as molar pregnancy by the presence of vesicles in the uterine cavity.

According to ultrasound diagnosis, out of 100 cases, 13 (13\%) were diagnosed as threatened abortion, 27 (27\%) as incomplete abortion, $22(22 \%)$ as missed abortion, 9 (9\%) as complete abortion, $7(7 \%)$ as anembryonic gestation, $9(9 \%)$ as ectopic pregnancy and $10(10 \%)$ as molar pregnancy.

Table 3: The causes of bleeding per vagina in first trimester of pregnancy.

\begin{tabular}{|lll|}
\hline Causes & Number & Percentage \\
\hline Abortion & 81 & 81.0 \\
\hline $\begin{array}{l}\text { Ectopic } \\
\text { pregnancy }\end{array}$ & 9 & 9.0 \\
\hline Hydatiform mole & 10 & 10.0 \\
\hline Total & 100 & 100.0 \\
\hline Test statistics & $\chi^{2}=102.26 ; \mathrm{df}=2, \mathrm{p}=0.001$ \\
\hline
\end{tabular}

The above table shows that major cause for bleeding per vagina in first trimester is abortion. In the present study, $81 \%$ had abortion as the major cause. The second cause is molar pregnancy constituting $10 \%$ followed by ectopic pregnancy which constitutes $9 \%$.

In present study, out of 44 cases which were clinically diagnosed as threatened abortion only 13 cases were sonographically confirmed as threatened abortion. There was disparity in 31 cases of threatened abortion which without the aid of ultrasonography, would not have received appropriate treatment . The disparity in case of incomplete abortion was 4 and in missed abortion was 13.7 cases of anembryonic gestation were solely 
diagnosed by ultrasonography. The disparity in cases of ectopic was 5 , in cases of complete abortion it was 2 and in case of molar pregnancy disparity was 9. The total disparity between clinical diagnoses and ultrasound diagnosis was 72 cases which accounts for $72 \%$.

In present study, there is significant disparity between clinical diagnosis, ultrasound diagnosis and final diagnosis. Ultrasound diagnosis has got greater reliability. There is $100 \%$ sensitivity of ultrasound diagnosis in all cases.

Out of 100 cases, 22 were managed conservatively, 54 underwent manual vaccum aspiration, 10 underwent suction and evacuation, 5 underwent instrumental evacuation and 9 cases of ectopic pregnancy underwent laparotomy.

We have divided our study group into 3 main categories for of statistical correlation. The 3 groups are:

- Viable intrauterine pregnancies.

- Nonviable intrauterine pregnancy.

- Ectopic pregnancy/gestation.

The groups were formed on the basis of the subsequent line of management in the particular cases. All cases of viable intrauterine pregnancy were to be followed up without intervention; while other cases were managed as appropriate based on the ultrasound findings.

A total 10 out of 45 cases of suspected viable intrauterine gestation on clinical examination were confirmed whereas it has got high false positive cases $(n=31)$. This shows a sensitivity of $76.92 \%$, specificity $64.36 \%$, PPV of $24.39 \%$, and accuracy of $66 \%$ with $p$ value of 0.012 .

Of the 4 ectopic pregnancies diagnosed clinically, all were confirmed with specificity of $100 \%$ and PPV of $100 \%$ and accuracy of $91 \%$ with a $p$ value 0.010 . In diagnosing non-viable pregnancies, clinical diagnosis has got very poor statistical correlation with sensitivity of $77.58 \%$, specificity of $83.33 \%$, NPV of $86.53 \%$ and accuracy of $80 \%$ with $\mathrm{p}$ value of 0.015 . In the present study, 13 cases of viable intrauterine pregnancies were correctly diagnosed on ultrasound with zero false positive and zero false negativity with sensitivity, specificity, PPV, NPV and accuracy of $100 \%$ each. $98.9 \%$ of ectopic pregnancies were correctly diagnosed with a sensitivity and NPV of $100 \%$ whereas 1 case diagnosed as ruptured ectopic on sonography was unruptured with a specificity of $99.9 \%$ and PPV of $90 \%$ with an accuracy of $99 \%$. Of the nonviable pregnancies diagnose on ultrasound all were confirmed with a sensitivity, NPV specificity, PPV and accuracy of $100 \%$. Ultrasound diagnosis proved to be very accurate on statistical evaluation with a very significant $\mathrm{p}$ value of 0.000 .

\section{DISCUSSION}

Bleeding per vaginum in the first trimester is one of the most common emergency encountered which warrants for an ultrasound examination. The causes of bleeding are many and cover a spectrum of conditions ranging from a viable pregnancy to that of a non-viable one. Accurate diagnosis of the nature of pregnancy (viable or nonviable) can help institute the appropriate treatment. The sonographic landmarks of the first trimester of pregnancy have been well recognized which includes identification of gestational sac, fetal pole, fetal cardiac activity, movements, yolk sac and amnion. The invaluable role of these landmarks, gestational sac and fetal biometry in diagnosing abnormalities and predicting the pregnancy outcome has been clearly documented. Ultrasonography has opened new dimensions in early pregnancy bleeding so that specific treatment, medical or surgical, can be immediately instituted.

Clinical history and pelvic examination are inadequate in assessing the cause and the prognosis. Ultrasound thus plays a dominant role in such cases and aid in managing them in the most appropriate way.

Table 4: The comparison of different authors study and present study for incidence of bleeding in first trimester.

\begin{tabular}{|l|l|}
\hline Study group & Percentage \\
\hline Scott $^{3}$ & $20-25$ \\
\hline${\text { Funderbert et } \mathbf{a l}^{\mathbf{4}}}^{\text {Pandey }^{\mathbf{5}}}$ & 2 \\
\hline Present study & 15 \\
\hline
\end{tabular}

Table 5: Comparison of causes of bleeding in first trimester of pregnancy with few studies.

\begin{tabular}{|c|c|c|c|c|}
\hline Cause of bleeding & Rani et al $(\%)^{6}$ & $\begin{array}{l}\text { Bhargava et } \text { al }^{7} \\
(\%)\end{array}$ & Shivanagappa et $\mathbf{a l}^{8}(\%)$ & Present study (\%) \\
\hline Abortion & 61 & 81.6 & 83 & 81 \\
\hline Ectopic pregnancy & 21 & 13 & 13 & 9 \\
\hline Hydatiform mole & 18 & 4.35 & 4 & 10 \\
\hline
\end{tabular}


In the present study various abortions contributed to a major cause of first trimester bleeding constituting $81 \%$. In Rani et al, Bhargava et al study, Mamatha Shivanagappa et al study group also abortion is the leading cause of early pregnancy bleeding with an incidence of $61 \%, 81.6 \%, 83 \%$ respectively. ${ }^{6-8}$ The incidence of ectopic pregnancy is $9 \%$ and molar pregnancy is $10 \%$. But the incidence of ectopic pregnancy and molar pregnancy in Rani et al, Bhargava et al and Mamatha Shivanagappa et al study is $21 \%$ and $18 \%, 13 \%$ and $4.35 \%$ and $13 \%$ and $4 \%$ respectively. ${ }^{6-8}$
Table 6: The comparison of viable and nonviable pregnancies confirmed on ultrasound to other studies.

\begin{tabular}{|c|c|c|}
\hline Study & Viable (\%) & Non viable (\%) \\
\hline Hertz et al9 & 58 & 42 \\
\hline Nyberg et al ${ }^{10}$ & 44 & 52 \\
\hline Stabile et al ${ }^{11}$ & 64 & 36 \\
\hline $\begin{array}{l}\text { Schauberger } \\
\text { et al } \mathbf{a l}^{12}\end{array}$ & 28 & 72 \\
\hline Present study & 13 & 78 \\
\hline
\end{tabular}

Table 7: Comparison of clinical and USG diagnosis of few studies.

\begin{tabular}{|c|c|c|c|c|}
\hline \multirow{2}{*}{ Study } & \multirow{2}{*}{ Clinical diagnosis } & \multirow{2}{*}{ USG diagnosis } & \multicolumn{2}{|l|}{ Disparity } \\
\hline & & & Number & Percentage \\
\hline Prakash $^{13}$ & 58 & 24 & 34 & 50 \\
\hline Ghorade $^{14}$ & 63 & 43 & 20 & 68 \\
\hline Rani et al $^{6}$ & 100 & 58 & 42 & 42 \\
\hline Present study & 100 & 72 & 28 & 72 \\
\hline
\end{tabular}

Table 8: Comparison of USG accuracy with some of the studies available.

\begin{tabular}{|llll|}
\hline Causes of bleeding & Sofat et $\mathbf{a l}^{\mathbf{1 5}}(\boldsymbol{\%})$ & ${\text { Bharadwaj et } \mathbf{a l}^{\mathbf{1 6}}(\boldsymbol{\%})}^{\text {Present study }}$ \\
\hline Threatened abortion & 95.5 & 98.2 & 100 \\
\hline Missed abortion & 100 & 100 & 100 \\
\hline Incomplete abortion & 50 & 100 & 100 \\
\hline Complete abortion & - & - & 100 \\
\hline Blightened ovum & 100 & 0 & 100 \\
\hline Ectopic pregnancy & 87.5 & - & 100 \\
\hline H. mole & 100 & 100 & \\
\hline
\end{tabular}

In our study the incidence of viable pregnancies on ultrasound is $13 \%$ and $78 \%$ of nonviable pregnancies. Hertz et al, Nyberg et al and Stabile et al had an incidence of $58 \%, 44 \%$ and $64 \%$ of viable pregnancies and $42 \%$, $52 \%$ and $36 \%$ of non-viable pregnancies respectively..$^{9-11}$

In our study, 100 clinically diagnosed cases were confirmed on ultrasound with disparity of $72 \%$. The present study is comparable to Ghorade study which is of $68 \%$. Khanna, Rani et al of $50 \%$ and $42 \%$ between clinical and ultrasound diagnosis respectively. ${ }^{14,13,6}$

In our study all cases of threatened abortion, missed abortion, incomplete abortion, complete abortion, anembryonic gestation and molar pregnancy were diagnosed accurately on ultrasound with accuracy of $100 \%$. The results of present study are comparable with Sofa et al and Bharadwaj et al in diagnosing missed abortion, incomplete abortion, anembryonic gestation and Hydatiform mole with $100 \%$ accuracy. ${ }^{15-16}$

\section{CONCLUSION}

In the present study, USG played a very important role in the diagnosis of cause of first trimester bleeding. It can diagnose threatened abortion positively. Missed abortion, anembryonic gestation and incomplete abortion, ectopic gestation and molar pregnancy are reliably diagnosed. Patient with complete abortions were accurately identified, so that unnecessary curettage was avoided with a consequent reduction in morbidity. Therefore ultrasound diagnosis in first trimester bleeding is a key diagnostic tool. Ultrasonography has helped in establishing the correct diagnosis of clinically misdiagnosed cases, confirm the diagnosis in the others and provide the most appropriate management in all of them. Today, Ultrasound definitely has an edge over clinical diagnosis in evaluating the cause for bleeding in the first trimester and can be rightly expressed as a component of the obstetrician's diagnostic armamentarium.

\section{Funding: No funding sources}

Conflict of interest: None declared

Ethical approval: The study was approved by the Institutional Ethics Committee

\section{REFERENCES}

1. Cunningham FG New York, Mc Graw-Hill editor. Williams's obstetrics 21 ${ }^{\text {st }}$ edition; 2001:866. 
2. Dighe M, Cuevas C, Moshiri M, Dubinsky T, Dogra VS. Sonography in first trimester bleeding. J Clin Ultrasound. 2008;36(6):352-66.

3. Scott JR. Ultrasound in first trimester, Evaluation of early bleeding. British J Obstet Gynaecol. 1999;23:45-9.

4. Funderbert et al, First trimester bleeding. Clinics OBG. 2000:24;59-71.

5. Pandey K, Arya S, Tyagi G. Pregnancy outcome in patients with first trimester vaginal bleeding. Asian J Obs Gynaec. 2000;2:34-8.

6. Reddirani P, Sunita V. Ultrasound evaluation of cause of vaginal bleeding in first trimester of pregnancy. J Obstet Gynecol Ind. 2000;50(1):54-8.

7. Bhargava SK, Dimri R. Transvaginal sonography in Obstetrics and Gynaecology, New Delhi, India 1988;44:97-159.

8. Mamatha S, Sagar SG, Manoli N. Ultrasound evaluation of vaginal bleeding in first trimester of pregnancy: a comparitive study with clinical examination. Int J Sci Stud. 2015;3(7):202-6.

9. Hertz JB, Mantoni M,Svenstruck B. Threatened abortion studied by estradiol 17 beta in serum and ultrasound. Obstet Gynecol. 1980:55;324-8.

10. Nyberg DA, Laing FC, Filly RA, Simmons MUN, Jeffrey RB. Ultrasonographic differentiation of the gestational sac of early intrauterine pregnancy from pseudo gestational sac of ectopic pregnancy. Radiol. 1983;146:755-9.

11. Stabile I, Campbell S, Grudzinskas JG. Ultrasonic assessment of complication during first trimester of pregnancy. Lancet. 1987;2:1237-40.

12. Charles W. Schauberger, Michelle A. Mathiason, and Rooney BL. Ultrasound assessment of first trimester bleeding; Obstet Gynecol. 2005;105:333-8.

13. Khanna A, Prakash C, Agarwal A, Khanna AK. Ultrasonography in the diagnosis of bleeding per vaginum during pregnancy. J Obst Gynaecol. 1992;42:120-3.

14. Gorade TG. Shorothri AN. Ultrasonography in early pregnancy bleeding. J Obstet Gynaecol India. 1991;41:13-6.

15. Sofat R. Ultrasound evaluation of bleeding in early pregnancy. J Obst Gynaecol India. 1987;31:344-7.

16. Bharadwaj N. Sonography evaluation as an aid in the management of bleeding in early pregnancy. J Obst Gynaecol Ind. 1988;38:640-2.

Cite this article as: Sandyashree PK, Nayak SCV. Clinical study of role of Ultrasound in first trimester vaginal bleeding. Int J Reprod Contracept Obstet Gynecol 2020;9:4010-5. 